\title{
EXPERIENCE AND Time: Transparency AND PRESENCE
}

\author{
CHRISTOPH HOERL \\ University of Warwick
}

Philosophers frequently comment on the intimate connection there is between something's being present in perceptual experience (call this experiential presence) and that thing's being, or at least appearing to be, temporally present (call this temporal presence). Yet, there is relatively little existing work that goes beyond asserting such a connection and instead examines its specific nature. In this paper, I suggest that we can make progress on the latter by looking at two more specific debates that have hitherto been conducted largely in isolation from each other: one about the nature of conscious experience and one about the nature of time itself. The first concerns the extent to which the temporal properties of experience form an exception to the transparency of experience, meaning that introspection can provide support for one particular view of how experience itself is structured temporally; the second concerns the question as to whether there is something about experience that gives us grounds for thinking that the present is somehow metaphysically special. As I argue, the idea of a connection between experiential presence and temporal presence plays a key background role in each of these debates. Yet it can also, in each of them, be seen to draw one side towards making claims that are supposed to express an important truth but are at the same time, on the face of it, self-contradictory. In each case, resolving what it actually is that these claims are trying to get at turns on recognizing a distinctive feature of perceptual experience, which I refer to as its lack of temporal viewpointedness. Recognising this feature also helps in making sense of what the issues at stake actually are in the intuition of an intimate connection between experiential presence and temporal presence.

P HILOSOPHERs frequently comment on the intimate connection there is between something's being present in perceptual experience and that thing's being (or at least appearing to be) temporally present. ${ }^{1}$ Brian $\mathrm{O}^{\prime}$ Shaughnessy (2000:

1. It is a familiar point that, due to the finite speed of light and sound, there is in fact a time-lag before distal events impinge upon our senses, though in the context of ordinary interactions with

Contact: Christoph Hoerl <C.Hoerl@warwick.ac.uk> 
49), for instance, speaks of being convinced "that the bond between time and experience is of great significance" and shortly after elaborates on this by saying that what is distinctive about conscious perceptual experience is that it puts its subject into a "special cognitive relation to the present moment, not accessible to non-experiencers" (2000: 50). Similarly, J. J. Valberg writes of an

intimate connection between experiential and temporal presence. We have a strong inclination to view objects that are present in experience as being, at that very time, existent: if something is now present, it now exists. This inclination to encompass the object within the temporal present does not extend to reference, or thought in general. There is no problem about referring to, or thinking of, objects which no longer exist. But our inclination is to say that such things cannot be present in experience, that they cannot now be objects of experience. (1992: 5)

Provisionally, we could put the thought at issue here by saying that it appears somehow essential to the nature of perceptual experience that it is the seeming disclosure of things as they are in the present. More specifically, this apparent connection between experiential presence and temporal presence (to adopt Valberg's terms) seems to be part of what accounts for the distinctive phenomenal character of perceptual experience. ${ }^{2}$ Yet, in so far as ideas such as these are already a theme in the existing philosophical literature on perceptual experience, the existence of such a connection between experiential and temporal presence is typically just asserted. There is relatively little work that examines in detail what exactly the connection consists in.

This relative lack of philosophical interest in the connection between experiential and temporal presence would perhaps be understandable if the nature of that connection was simply obvious. In particular, it might be thought that the nature of that connection is obvious because the things presented to us in perceptual experience are simply presented to us as temporally present. Part of what I want to argue in this paper, though, is that it would be a mistake

things in our environment this time-lag is usually too short to be of practical relevance (Butterfield 1984; Dummett 1973: 388). Hence the qualification, which I will sometimes omit in what follows.

2. See also, for instance, Paul (2010). Echoing Valberg's talk of an 'intimate connection', she speaks of "an intimate connection between the subjective force of our experiences as of, say, redness and the subjective force of our experiences as of the nowness ... of events" - or, as she also puts it, between the "oomph of consciousness" and the "oomph of nowness" (Paul 2010: 340). Historically, similar ideas can be seen to form an important theme in Husserl's (1893-1917) writings on time-consciousness - at least in so far as Husserl subscribes to a principle that Miller (1984) terms the Principle of Presentational Concurrence-as well as in Russell's (1912; 1913) writings at the time at which he developed the doctrine of perceptual experience as acquaintance with sensedata, and in Broad's (1925) 'sensum theory'. 
to think so. In fact, there is an important sense in which the things presented to us in perceptual experience are not presented to us as present or under any other 'temporal mode of presentation'. ${ }^{3}$ As I will call it, one distinctive feature of perceptual experience is that it is not temporally viewpointed, ${ }^{4}$ and getting it right about the special connection between experiential presence and temporal presence, perhaps somewhat paradoxically, turns precisely on recognising this distinctive feature of perceptual experience.

Before setting out my positive argument, though, I will take a brief critical look at two more specific existing debates in each of which the idea of a connection between experiential and temporal presence can be seen to play a key background role, but which so far have been conducted largely in isolation from each other. The first of these debates concerns the extent to which the temporal properties of experience form an exception to the transparency of experience, which would mean that introspection can provide grounds for a particular view of how experience itself is temporally structured. The second debate concerns the extent to which the phenomenology of conscious perceptual experience lends support to a particular view of the nature of time itself, in particular to the idea that the present is somehow metaphysically special.

My motivation in looking at these two more specific debates is to overcome a methodological difficulty: As much as the idea of an intimate connection between experiential presence and temporal presence is already a theme in the existing philosophical literature-along, at least sometimes, with the idea that this connection goes to the very heart of the nature of perceptual consciousness - the substance behind it can nevertheless come to appear elusive if all we have to go on is the basic intuition that there is such a connection. (This may well be one of the reasons why much of the existing literature touching on this issue doesn't get very far beyond simply asserting the connection.) After all, it might be argued that how things are with us experientially also encompasses what we remember-that is, an awareness of the past-and perhaps even what we

3. As I explain in more detail in Section 3, below, we can, of course, become aware that perceptual experience de facto only presents us with events that are temporally present, because there are also other events we can remember or anticipate but which we can no longer or not yet perceive. Our being thus equipped with capacities for memory and anticipation can also explain how we can arrive at present-tensed judgements on the basis of perceptual experience. But the claim here is different. It is concerned specifically with what is manifest to us within perceptual phenomenology itself.

4. Variants of the idea that perceptual experience is not temporally viewpointed, as I call it here, can also be found discussed in Hoerl (1998; 2009), Grush (2016), and at least under one interpretation Le Poidevin (2007: Chapter 5). The idea has as yet not been explicitly linked to the idea of a connection between experiential and temporal presence in the way I do in this paper. However, I take it that what I suggest below fits in well, e.g., with the way in which considerations about the tight connection between experience and action lead Grush (2016: 1) to the conclusion that "temporal experience is B-ish at small scales", as he puts it. 
anticipate - that is, an awareness of the future, in at least some sense of the term. So, on this understanding, the claim that only what is present features in our experience can actually come to seem false. The obvious move to make in response to this point, of course, is to narrow down the intended scope of the term 'experience'. But whilst I think it is of course correct to view the claim about the intimate connection between experiential and temporal presence as one restricted specifically to perceptual experience, this move, in turn, can come to make it look as though the difference between memory, anticipation and perceptual experience simply boils down to the difference in which portions of time they make us aware of. And if that was the case, it would render it somewhat mysterious why the claim that there is an intimate connection between experiential and temporal presence is a claim worth making in the first place. Arguably, what makes it a claim worth making is the idea of a phenomenological difference that goes deeper than this, between the sui generis type of awareness we have, in perceptual experience, of what is present, and other ways in which we can also be aware, in memory and anticipation, of what is past and of what is still to come.

It is for this reason that I start by looking at the two somewhat more specific debates that I will discuss in the following two sections. As I want to show, doing so can help us get a better purchase on some more substantive questions about the nature of the connection between experiential and temporal presence, because in each of these debates one side finds itself drawn to making claims that seem, at least prima facie, self-contradictory, but which, at the same time, are supposed to express an important truth linked to the idea of such a connection. It is one and the same source, I want to suggest, that each of these sets of claims can be traced back to. In each case, the key feature of the phenomenology of perceptual experience that the relevant claims are actually trying to get at is its lack of temporal viewpointedness. And recognizing this feature also helps in making sense of what the issues at stake actually are in the intuition of an intimate connection between something's being present in experience and its being temporally present.

\section{Temporal Experience and Transparency}

In two much-quoted passages in 'The Refutation of Idealism', G. E. Moore writes:

That which makes the sensation of blue a mental fact seems to escape us; it seems, if I may use a metaphor, to be transparent - we look through it and see nothing but the blue. (1903: 446) 
The moment we try to fix our attention upon consciousness and to see what, distinctly, it is, it seems to vanish: it seems as if we had before us a mere emptiness. When we try to introspect the sensation of blue, all we can see is the blue: the other element is as if it were diaphanous. (1903: 450)

Following Moore, philosophers often speak of the idea of the transparency of experience. Typically, two readings of this idea are distinguished-a weaker one on which it encompasses only a positive thesis, and a stronger one on which it encompasses both a positive and a negative thesis. According to the positive transparency thesis, when we try to focus on the nature of our own ongoing conscious experiences, our attention invariably lands on the objects and properties they are experiences of. When I look at a blue object, to use Moore's example, the only way I have of trying to fix my attention on the nature of my experience of its colour is by attending to the blue object in front of my eyes. On its own, though, the positive transparency thesis is neutral on whether or not it is also exclusively that object and its properties I can attend to, or whether I might also, in doing so, be able to attend to some properties possessed not by that object, but by my own experience of its colour. The latter is just what the further, negative, transparency thesis denies is possible. That is to say, according to the negative transparency thesis, when we try to focus on the nature of our own experiences, we do not become aware of anything other than the objects they are experiences of and the properties of those objects; in particular, we do not become aware of any properties of our experiences themselves. 5

There is a great deal of existing debate regarding the extent to which the negative transparency thesis is true. In what follows, I will largely leave aside arguments against the negative transparency thesis concerned with non-temporal features of experience. ${ }^{6}$ My main focus will be on the idea that there is a special reason for thinking that the negative transparency thesis fails to hold for temporal properties of experience in particular. More specifically, I want to examine the idea that the intuition of an intimate connection between experiential presence and temporal presence provides such a special reason.

Michael Tye, who subscribes to a strong reading of the idea that experience

5. That's to say, of course, any properties other than simply the property of being an experience of such-and-such objects and such-and-such properties of those objects. I should also clarify that, whilst it may sound as though Moore, in the passages I have quoted from him, endorses the negative transparency thesis, he actually goes on to claim that what he calls the 'other element' "can be distinguished if we look enough, and if we know that there is something to look for" Moore (1903: 446). In terms of the above distinction, Moore himself would thus deny the negative transparency thesis.

6. Here I am thinking, for instance, of the phenomenon of blur, which is sometimes invoked to argue against the negative transparency thesis. See, e.g., Crane (2006) and Allen (2013). 
is transparent-encompassing both the positive and the negative transparency thesis-has explicitly argued that such transparency extends to the temporal properties of experience too. 7 He says, for instance, the following:

Consider ... the case in which I have an experience of a red flash followed by a green flash. Here I experience two flashes as occurring one after the other. I do not experience my experience of a red flash as succeeding my experience of a green one any more than I experience my experience of a red flash as red.... What is true here for the experiences of red and green flashes is true for other experiences. If I experience a loud, high-pitched sound, it is the auditory qualities of the sound that are experienced as continuing from moment to moment; if I feel a pain in a thumb, it is the changing qualities of the disturbance I experience in my thumb that are experienced by me, as the pain starts to throb and intensify. Continuity, change, and succession are experienced as features of the items experienced, not as features of experience. (Tye 2003: 96f.)

Even if one endorses the general idea of the transparency of experience, one worry one might have about this way of applying it also to temporal aspects of experience is that it fails to do proper justice to the intuition of an intimate connection between experiential presence and temporal presence. At least prima facie, this intuition can appear to go against the grain of the negative transparency thesis. If we accept that what we have sensory awareness of ipso facto strikes us as being temporally present, it seems that, as part of our being sensorily aware of an occurrence, it must also appear to us that our awareness itself is concurrent with that occurrence. Add to this that we can be sensorily aware of occurrences unfolding over time, and it seems that, as part of such episodes of awareness, it must appear to us that the episodes of awareness in question are themselves unfolding over time.

Thoughts along these lines seem to be behind the following remarks by Ian Phillips - interestingly, though, he does not frame them in terms of the idea that the temporal properties of experience form an exception to negative transparency, but rather in terms of the idea that the notion of the transparency of experience has to be unpacked in a special way when it comes to temporal features of experience:

[The idea of the] transparency of temporal experience ... can be broken down into two components. Firstly, there is the claim that when we set-

7. For forceful expressions of views along similar lines, see also Millikan (1991) and Dennett and Kinsbourne (1992). 
out to describe our experience itself, we find ourselves doing so, at least partly, by attending to its objects. And what we find of current relevance is that there are objects of attention which we cannot attend to without attending to goings on over a period of time. Arguably, this is true of all objects of attention. But it is certainly true of some, such as sounds or movements.

Parties to the present debate will likely accept [this first transparency claim]. It is the second transparency claim which only some find compelling. This is the claim that it seems to us that our experience itself unfolds alongside, and in step with, the temporal phenomena which we find ourselves attending to in reflecting on our experience. (Phillips 2014a: 132)

Note that what Phillips describes as the first transparency claim is simply the positive transparency claim that is typically accepted on all sides in discussions of perceptual experience, and which is accepted as a claim about perceptual experience in general, and not just its temporal aspects.

Phillips describes his second claim, which is supposed to apply specifically to the temporal aspects of experience, as a 'transparency claim', too. However, it is actually far from obvious in what sense it should be seen as affirming a form of transparency, and how it relates to the kinds of claims standardly made in the literature on the transparency of perceptual experience. Depending on how the phrase 'it seems to us' is to be understood (which is an issue I will return to), the second claim might in fact be seen to amount to a denial of transparency for the case of the temporal properties of experience, implying that certain aspects of the metaphysical nature of experience itself are (or at least seem to be) open to introspection. When reflecting on experiences of temporal phenomena such as movements or melodies, it suggests, those temporal phenomena are not in fact the only thing we can become aware of; there is also a sense in which we can (at least seemingly) become aware of our own experiences of them as having certain properties - namely the properties of being temporally extended and structured, in a way that mirrors the temporal extension and structure of the phenomena they are experiences of. Yet, Phillips seems to take this to be compatible with there being a sense in which the idea of the transparency of experience still enters into the second claim, too, in so far as the claim is that our awareness of the temporal properties of our own experiences is mediated by, and dependent upon, attention to the temporal properties of the things they are experiences of.

We seem to find a similar sort of view expressed also by Matthew Soteriou, who writes as follows:

When one introspects one's experience, the temporal location of one's perceptual experience seems to one to be transparent to the temporal 
location of whatever it is that one is aware of in having that experience. Introspectively, it doesn't seem to one as though one can mark out the temporal location of one's perceptual experience as distinct from the temporal location of whatever it is that one seems to be perceptually aware of. Furthermore, it seems to one as though the temporal location of one's experience depends on, and is determined by, the temporal location of whatever it is that one's experience is an experience of. (2013: 89f.)

This passage follows some remarks that explicitly refer to and summarize some of the existing literature on the general idea of the transparency of experience. Note, though, that just like Phillips, Soteriou uses the notion of transparency in a somewhat idiosyncratic fashion when it comes to talking about temporal features of experience, in particular when he speaks of the temporal location of one's experience being 'transparent to' the temporal location of what is being experienced. In the rest of the literature on the transparency of experience, what is typically described as being transparent is simply experience itself, the point being precisely that transparency (at least where it obtains) scuppers attempts to attend to properties perceptual experiences themselves possess, our attention instead landing on the properties of experienced worldly goings-on. Soteriou, by contrast-again, like Phillips - might be read as claiming that there need be no bar to saying, with respect to temporal properties of experience, that they are in some sense transparent, but also that we can attend to them as temporal properties of our experiences, and as being (apparently) determined by temporal properties of the objects of experience.

Thus, both authors seem to want to assert the general idea of the transparency of experience, but, in explaining how this idea applies to temporal features of experience, it at least looks as though they actually end up denying transparency at the same time. It may, of course, be the case that they simply mean to assert the positive transparency thesis with respect to the temporal features of perceptual experience, but to deny the negative transparency thesis (as well as perhaps making some additional claims about the relationship between the temporal features of experience and the temporal features of the things being experienced). ${ }^{8}$ But then it is interesting that they don't straightforwardly state

8. Two anonymous referees both suggested that this might in fact be the most plausible reading of their remarks. Apart from exegetical problems of the kind I go on to outline, what prevents me from sharing this view is that I wouldn't consider it the most charitable reading, as will become clearer in the second half of this paper. As I will argue, in so far as Phillips and Soteriou can be seen to hold back from a blunt denial of negative transparency for the temporal properties of experience, they are in fact right in doing so. Connectedly, the suggested reading would reduce the dialectic between them and authors such as Tye, who endorse a strong version of the negative transparency claim, to a simple clash of phenomenological intuitions, whereas I think that there is 
their view in those terms. ${ }^{9}$ Consider, for instance, the following characterization Phillips gives of why, in his view, "the transparency thesis looks rather different in the temporal case" (2009: 56), as he also puts it elsewhere. As he says,

time is special. Temporal properties are the only properties manifestly shared by both the objects of experience and by experience itself. Experience, at least in its subjective aspect, is not coloured or shaped; it does, however, manifestly have a temporal structure. As a result, the question arises of the relation between the temporal structure of experience and the temporal structure of its objects. No such question arises for colour or shape. (Phillips 2014b: 139)

It seems to me that there is at least some measure of tension between Phillips's claiming that the temporal properties of experience are manifest to us, and his also appearing to treat the question as to the relationship between the temporal structure of experience and that of its objects as a further, open question. If the temporal properties of experience are indeed as manifest to us as those of the objects of experience, the nature of that relationship should simply be obvious to us. ${ }^{10}$ Thus, it is at least questionable whether Phillips's attempt to account for a sense in which 'time is special' when it comes to experience by pressing into service the idea of the transparency of experience lands him with a stable position, rather than one that ends up asserting transparency whilst denying it at the same time.

As I have argued, both Phillips's and Soteriou's similar position can be seen to be motivated by the aim of doing justice to the intuition of an intimate connection between experiential presence and temporal presence. Is there a way of doing so without running into the problems they appear to face? I will return to this issue in Section 3, where I will also argue that considerations about transparency are in fact relevant to it. To anticipate, I will ultimately suggest that the truth both Phillips and Soteriou are trying to get at by seemingly denying transparency for the temporal properties of experience is in fact better captured by saying that, when it comes to time, there is a sense in which the transparency of experience applies to a particularly strong degree. The same set of considerations, I will also argue, can help clarify the issues at stake in a second debate in which the idea of an intimate connection between experiential and temporal presence seems to play a key role, which I will turn to next.

a more interesting diagnosis available as to what it actually is about experience that Phillips and Soteriou are trying to get at.

9. Elsewhere, Soteriou (2013: 118f.) does precisely that when talking about features of perceptual experience connected to its spatial character.

10. On related issues, see also Frischhut (2014) and Lee (2014). 


\section{Experiential Presence, Temporal Presence, and the Metaphysics of Time}

The preceding section was concerned, in part, with the question as to whether considerations about the phenomenology of temporal experience-in particular, about the apparent close connection between experiential presence and temporal presence-can provide us with grounds for endorsing a particular view of the nature of experience, namely, that experiences are themselves temporally extended and structured. Interestingly, what, on the face of it, look like much the same considerations about the phenomenology of experience are also sometimes claimed to provide us with grounds for endorsing a particular view of the nature of time itself.

One particular kind of claim that has been made in the latter context, which will be my main focus in this section, is that the present is somehow metaphysically special, and that this special metaphysical status of the present explains the special place that temporally present things have in our experience. The idea that the present is metaphysically special is a central ingredient of the group of views sometimes referred to as the A-theory of time, but even supporters of the rival B-theory, who reject this idea, often agree with the thought that there is something about experience that suggests such a metaphysical picture, and spend a great deal of time trying to show why we should think of experience as misleading us in this respect.

Yet, in this context, too, the idea that there is something special about time that is, or at least seems to be, reflected in the phenomenology of experience appears difficult to state without contradiction. As Huw Price puts it, the view that the present is somehow metaphysically special

is trying to combine two elements, which pull in opposite directions. On the one hand, it wants to be exclusive, saying that one moment is objectively distinguished. On the other hand it wants to be inclusive, saying that all moments get their turn - their Warholian instant of fame, when the spotlight turns on them alone. (Everybody is a star.) (2011: 278)

In so far as A-theorists endorse the view that only the present is real, or that there is some other metaphysically unique status that the present has, they of course also typically want to say that time passes, and that other moments in time get to be present as it does so-but that, it seems, is just to deny the idea of uniqueness.

Rather than thinking of this point as providing a knock-down argument against the A-theory, though, I believe we should see it as bringing us to the heart of the issue at stake in the debate between the A-theorist and the B-theorist. For the A-theorist will argue that it is precisely due to the very nature of time

$$
\text { Ergo • vol. 5, no. 5 • } 2018
$$


that the A-theory is difficult to state without contradiction. ${ }^{11}$ This is so because it follows from what the A-theory says about time that "we must abandon our prejudice that there must be a complete description of reality", as Michael Dummett (1960: 504) puts it at one point. Due to the passage of time, any description of reality we can in fact give is necessarily incomplete. Any 'tenseless' description of reality will leave out one important metaphysical fact: which moment is present. Yet, any 'tensed' description that can capture that fact will be such that other moments in time will only figure in it as ones that were or will be present, and will necessarily fall short of capturing the facts that their being present did or will consist in. In other words, any description of reality, in so far as we are capable of framing it, at best reveals the world as it is now. And it is precisely due to the nature of time-because how things are over time is changing - that this description is necessarily an incomplete one. Or so the A-theorist thinks. As brought out by Price's argument, however, this makes the A-theory difficult to state without contradiction: It wants to make a claim about temporal reality as such, that applies to the whole of temporal reality, whilst at the same time implying that no description we are actually capable of giving can in fact encompass the whole of temporal reality. ${ }^{12}$

Against this background, it is perhaps not surprising that it is also once again not easy to pin down what exactly the relevant feature of the phenomenology of experience is supposed to be that makes the A-theory seemingly compellingwhat it is about the apparent close connection between experiential presence and temporal presence that invites the thought that the present is metaphysically special.

Yuri Balashov (2005: 295), for instance, considers the following two candidates for the relevant feature that may initially seem promising: the fact that, when we have an experience and the question arises as to when this experience occurs, the answer is invariably that it occurs in the present-we know it to be present-and the fact that, in as far as we know an experience to be present, we are aware of it being present at the expense of others. As Balashov argues however-in my view correctly-these two features cannot in fact explain the supposed attraction of the A-theory.

11. Such contradictions are, of course, also at the heart of McTaggart's (1908) famous argument, which Price's argument is meant to be a gloss on.

12. A reviewer asks whether there isn't one kind of A-theorist, i.e., the presentist, who would say that a complete description of reality can be given, it's just that the facts change. According to presentism, only what is present is real or exists-there is therefore a sense in which the presentist might claim to be able to give a complete description of reality by describing what is present. The problem with this claim, though, is that it is not clear how the presentist can give substance to the idea that 'the facts change' unless they also operate with a wider notion of 'reality', i.e., a reality also containing facts that do not figure in that description because they are not present facts. See also Leininger (2015) and Fine (2006) for related arguments. 
Balashov's own argument is that these two features, on their own, do not 'break the parity' between different experiences at different times in the way envisaged by those who think that the phenomenology of temporal experience lends support to the idea that the present is metaphysically special. If anything, I think this understates the issue. In so far as we know each experience to be present when it occurs, and present to the exclusion of others, this should in fact lead us to judge that the relevant difference between the past, the present and the future is purely a matter of perspective. That is of course just how the B-theorist thinks things stand metaphysically, but the point here is that this is also how things would appear to us, if these two features were all there is to the temporal phenomenology of experience. It would be manifest to us that, at each time, we have the particular experience we have at that time only because it is the time when we have that experience, not because there is something further, metaphysically special, about that time. ${ }^{13}$

Is there any other feature of the phenomenology of conscious experience that can provide a better candidate for the feature at issue in the debate over whether experience favours the idea that the present is metaphysically special? Balashov suggests it is what he calls 'Occurrence'.

What really breaks the parity is knowledge that some experiences occur, not merely when they do (and when they are known at the expense of others), but now. Your reading this paper is a case in point. Its occurrence does not appear to be just a matter of being correlated with a possible A-belief about its presentness, as opposed to pastness and futurity - a feature that it shares with your having breakfast this morning and your enjoying a concert later tonight. In addition, your reading this paper appears to be occurring simpliciter. Call this feature Occurrence. (Balashov 2005: 295)

Balashov later also describes Occurrence as the "sense in which some experiences are known to be occurring, or present, as opposed to not occurring, or absent" (2005: 295), noting that 'present' here carries a different meaning from the temporal one. This perhaps shows that his initial framing of Occurrence in terms of the idea that we know some experiences to occur now does not quite get at the issue. Balashov's claim rather seems to be that, in order to get right the feature of the phenomenology of experience that motivates the A-theorist, we need to acknowledge a sense in which the events we experience at each moment in time

13. Strictly speaking, this would still not rule out the truth of the A-theory, of course. It would just mean that we wouldn't feel any temptation to think that the truth of the A-theory was required in order to explain aspects of our experience. I am grateful to an anonymous referee for pressing me on this. 
are precisely not experienced by us as present at just that moment (which would make it manifest to us that those particular events figuring in our experience at that moment is simply due to it also being the moment when we have the relevant experience), but in a way that is somehow not temporally qualified at all. ${ }^{14}$ It is in this sense that sensory experience might be said to present us with things simply as occurring, and that is what is distinctive about sensory experience.

Some philosophers respond with incredulity to some of the phenomenological claims A-theorists make on behalf of the A-theory. Here, for instance, is Craig Callender complaining that he finds Balashov's notion of Occurrence unintelligible:

The question then is, what is the experience tensers [i.e., A-theorists] want to appeal to? . . Balashov 2005, for example, tries hard to identify this experience ... . He says tenseless accounts to date miss the crucial feeling, the feeling of events "simply occurring" (295). What is it to simply occur? Balashov struggles to say. . . . Later Balashov settles on the "distinctive aspect" of occurrence as the alleged fact that "present experiences are known to be occurring simpliciter, in addition to occurring when they are" (298). This again pushes our question back: what is occurring simpliciter? The answer is more Latin - the experience, he says, is "sui generis" (298) - but we never get more lumen. (Callender 2008: 344)

Something like Callender's response is perhaps not surprising if, as I have sought to bring out, the view of time that is supposedly suggested by the feature of phenomenology Balashov calls Occurrence is itself difficult to state without contradiction. ${ }^{15}$ But it once again seems to leave us in an impasse, just as in the case of the debate as to whether the temporal properties of experience constitute

14. Compare also Skow's (2011) discussion of what he calls 'the Argument from the Presented Experience'. A-theorists or B-theorists trying to understand the motivation behind the A-theory sometimes also write of our experience of the NOW, which might at first appear to be in conflict with these claims, but can, I think, actually be seen to imply an endorsement of them. Implicit in the use of the capitalized and nominalized NOW seems to be the idea that it is de facto true that experience presents us exclusively with what is present, but that this is, at the same time, not a matter of experience presenting us with things in a way that involves an equivalent to the temporally qualifying indexical 'now'. See also the next section for further discussion.

15. I should also mention that the passage I have quoted from Callender may make him sound more dismissive than he in fact is of the need for B-theorists to engage with the kinds of intuitions about our experience of time that A-theorists appeal to. Indeed, the bulk of the paper in which that passage occurs is explicitly taken up with the task of providing an explanation, in B-theoretic terms, of some other "very powerful intuitions [we have] supporting the view that reality is divided into past, present and future, and that this is so not merely relative to one's current perspective" (Callender 2008: 345). In that respect, my project in part of what follows is somewhat continuous with Callender's - though perhaps I am more willing than he is to grant that Balashov has succeeded in putting his finger on one of the relevant target explananda.

$$
\text { Ergo • vol. 5, no. 5 • } 2018
$$


an exception to transparency, with one side insisting that there is something unique about the temporal aspects of experience that motivates their position, but seemingly without being able to state what this unique phenomenological feature is in a way that can be made readily coherent. In the next section, I want to suggest that there is a way of overcoming that impasse, and that it is in fact the same for each of the two cases.

\section{Understanding the Connection - A Suggestion}

In the preceding two sections, I discussed two interpretative puzzles arising within the context of a debate about temporal experience and a debate about the metaphysics of time, respectively. In each of the two debates, proponents on one side of the debate seem forced to admit that they cannot articulate their position without involving themselves in contradiction, yet they will insist that this is precisely because of an important sense in which 'time is special' that they are trying to capture, which is supposedly manifest in experience. ${ }^{16}$

Thus, Phillips and Soteriou appear to want to say that, as far as the temporal properties of experience are concerned, there is an important sense in which experience both is and isn't transparent. Similarly, as we have seen, A-theorists such as Balashov maintain that present events are experienced by us as simply occurring, in a way that makes them stand out as unique amongst all other events; yet it is also clear that all other experienced events in fact have the same experiential status at the time they were or will be experienced, contradicting the idea of uniqueness.

Dialectically, though, it seems wrong simply to dismiss these views on the grounds of contradiction, because that looks like simply denying that there is something important to the intuition that can be seen to inform both of them, of there being an intimate connection between experiential presence and temporal presence. In what follows, I want to argue that it is in fact one and the same feature of the phenomenology of perceptual experience that both sets of authors are trying to get at, and which leads them to make what look like contradictory statements both about the nature of experience and about the nature of time itself.

Let me start by returning to a passage from Soteriou that I have already quoted above:

16. A vivid, Bergson-inspired, polemic against 'intellectualism's' failure to capture 'sensational immediacy' adequately can already be found in James (1909: Lecture VI), in the final paragraph of which James states the following:

Of course this sounds self-contradictory, but as the immediate facts don't sound at all, but simply are, until we conceptualize and name them vocally, the contradiction results only from the conceptual or discursive form being substituted for the real form. (1909: 272) 
When one introspects one's experience, the temporal location of one's perceptual experience seems to one to be transparent to the temporal location of whatever it is that one is aware of in having that experience. Introspectively, it doesn't seem to one as though one can mark out the temporal location of one's perceptual experience as distinct from the temporal location of whatever it is that one seems to be perceptually aware of. Furthermore, it seems to one as though the temporal location of one's experience depends on, and is determined by, the temporal location of whatever it is that one's experience is an experience of. (2013: 8gf.)

As I have interpreted this passage so far, it employs the terminology of transparency in talking about temporal aspects of experience whilst seemingly, at the same time, denying that the temporal properties of experience are transparent. Note, though, that, in so far as the passage just quoted can be read as an endorsement of a view of this kind, this turns on a particular way of understanding what Soteriou means by saying that things 'seem to one' a certain way.

In the context of talking about perceptual experiences, talk about how things 'seem' is sometimes used to indicate that a certain determinable property figures in one's experience, but also that the perceptual evidence that the experience provides as to the more determinate nature of that property is potentially misleading. (Think, for instance, of the sense in which the two parallel lines in the Müller-Lyer illusion 'seem' to be of different lengths.) It is an analogue to this reading of 'seems' which invites the thought that Soteriou, in the passage quoted above, effectively denies that the temporal properties of experience are transparent. On this reading - and it is not easy to read the final sentence of that passage in any other way - what he says is that the temporal location of one's experience features in introspection, and it features in it in a way that suggests that it "depends on, and is determined by, the temporal location of whatever it is that one's experience is an experience of" (Soteriou 2013: 90).

Yet, if we can indeed become introspectively aware of the temporal location of our experiences, it is rather odd to think that introspection might nevertheless mislead us about that location, so that we would have to hedge against this possibility by using the phrase 'it seems'. Thus, there are also reasons for thinking that this understanding of the phrase can't quite be what Soteriou is after. One alternative way in which 'seems' is sometimes used is to flag up that one is making a claim about how things are, phenomenologically, for the subject - that is, to describe an aspect of perceptual experience that contributes to what it is like, for the subject, to have the relevant experience. And here it is interesting to note that the first occurrence of the word 'seems' in the second sentence of the passage I have quoted appears to allow only for such a reading, or at least it is difficult to make much sense of the idea that it could also be intended in the sense described 
in the previous paragraph. In so far as it doesn't "seem to one as though one can mark out the temporal location of one's perceptual experience as distinct from the temporal location of whatever it is that one seems to be perceptually aware of" (Soteriou 2013: 89), this kind of feature of the phenomenology of experience simply doesn't appear to be the kind of thing one could potentially be wrong about. Here, the relevant sense of 'seeming' appears to be just the other one, in which it is used to flag up an aspect of the phenomenology of the experience.

What exactly is the subject matter this second sentence is concerned with? Note that, whilst this sentence is arguably concerned with a property of experience, at least in some sense of the term, that property is not a temporal property of experience of the type that is at stake in the debate over temporal experience and transparency as portrayed in Section 1, above. In fact, there are two crucial ways in which it is different.

First, the particular feature of perceptual experience that is really at issue in this second sentence is not a temporal attribute that perceptual experiences themselves possess as occurrences in time, such as their temporal duration, location and structure. Rather, it is the fact that perceptual experience is not, as we might put it, temporally viewpointed, where what I mean by this is specifically a phenomenological feature of temporal experience. Nerlich, I take it, is trying to describe the same aspect of the phenomenology of experience when he says at one point that there is "no counterpart of perspective in our perception of events and processes" (1979: 18). But we need to be careful how to understand the notion of a perspective in this context. It is, of course, de facto the case that perceptual experience presents us with events only in so far as they are present, and, being equipped also with the capacity to remember or anticipate non-present events, we can become aware of the fact that our access to reality through perception is restricted in this way, which is one way in which the notion of a 'perspective' may sometimes be used (that is, to capture only the idea of a restriction on what we are aware of). But the sense of 'viewpointedness' I (and I believe Nerlich, too) have in mind involves a different notion of perspective, which describes an aspect of the very way things are being experienced within perceptual experience. Compare, for instance, the way in which visual perception is spatially viewpointed. ${ }^{17}$ In visual experience, we can mark out the location from which the objects of experience are seen as different from the location of those objects. This means that, when we look at an array of objects, we see them in a particular way, which also allows for other ways in which the same array of objects could be seen, if they were seen from other locations. The sense in which perceptual experience

17. Here and in what follows, I will focus in particular on visuo-spatial experience, but it is arguable that experience in other sensory modalities too involves a spatial perspective. For discussion of the different ways in which it does so, and how they might relate to questions regarding the individuation of the senses, see Martin (1992) and Richardson (2010; 2014). 
lacks temporal viewpointedness, thus, is that there is no equivalent 'temporal point of view' that we could discriminate, from within experience, from the time of the experienced events, and thus no equivalent 'way' in which events figure in perception temporally that would also allow for other, alternative, ways in which the same events might figure in it. ${ }^{18}$

This brings me to the second sense in which I think the property at issue in the second sentence of the passage I have quoted from Soteriou is different from the kinds of properties of experience discussed in Section 1: It is a purely negative property, in the sense that it consists simply in the absence of an equivalent to a property that visuo-spatial perception, for instance, possesses, in so far as it is spatially viewpointed. In other words, what I am suggesting is that the reason why "it doesn't seem to one as though one can mark out the temporal location of one's perceptual experience as distinct from the temporal location of whatever it is that one seems to be perceptually aware of" (Soteriou 2013: 89) isn't that both of these locations figure in the phenomenology of experience, and are experienced as being identical, but rather that there is no such thing as the felt temporal location of the experience forming part of the phenomenology of experience. There is just no scope within a description of our experience of temporal properties for a distinction between those experienced properties themselves and a point in time from which they are experienced. ${ }^{19}$

Features of the phenomenology of experience such as the particular way in which visual experience is spatially viewpointed are sometimes also referred to as structural features of experience, reflecting in particular the spatial enabling conditions of perceptual experience corresponding to the different sensory modalities. As Louise Richardson explains, these structural features of experience are "a matter not of which things we perceive, but of how we perceive those things", thus allowing for different ways in which one and the same thing might be experienced (2014: 493). They also "stay the same when we re-arrange, change or take away the objects ... of which we are aware" (Richardson 2014: 493), in a way that is

18. See also Hoerl $(1998 ; 2009)$ and Richardson $(2014$ : 502). Soteriou, too, at one point remarks that, even though on his view we can perceive intervals of time, "there is a sense in which one's perceptual access to an interval of time doesn't seem to one to be perspectival" (2013: 131). My suggestion is that we should take this to be the fundamental feature that makes temporal phenomenology distinct, and that it is not to be confused with the idea that we have introspective access to temporal properties of experience. Also, my main focus is on this phenomenological claim, rather than on what might explain it. Some psychological considerations that might potentially be brought to bear on the latter question can be found in Falk (2003: 222ff.) and Grush (2016).

19. Contrast here also the spatial aspects of haptic perception. Unlike vision, touch isn't a distal sense, but there are nevertheless different ways in which an object can figure in haptic perception, depending on the place of our body we touch it with. This allows for distinguishing, as aspects of the phenomenology of haptic experience, between the felt location of the object and the location where we feel it, even if, in each instance of an object being felt, they roughly coincide in space. 
captured, for example, in the notion of a visual field. As such, structural features of experience should arguably be counted towards the properties of experience itself, rather than the things being experienced. The way visuo-spatial experience is spatially viewpointed, for instance, cannot simply be captured by talking about the spatial relationships that are being represented in the experience. ${ }^{20}$ Precisely because of the spatial viewpointedness of visual experience, saying that the spatial relationship between two given objects figures in our experience does not suffice to capture the nature of the experience, as there are many different ways in which this relation might figure in our experience, depending on our viewpoint. Similar considerations also apply to the proposal that we might be able to capture the way in which visuo-spatial experience is spatially viewpointed by saying that the spatial relations between the perceiver and the perceived objects are themselves also represented in experience. In so far as this is true, these relations figure in experience in quite a different way than the spatial relations that obtain between, say, one perceived object and another - a way that actually turns crucially on the perceiver not figuring in experience as such an object. ${ }^{21}$

If the structural features of experience are thus to be counted towards the properties of experience itself, rather than the things that are being experienced, ${ }^{22}$ they arguably constitute an exception to what I earlier called the negative transparency claim (perhaps the only one, but we need not commit ourselves to that for the purposes of the present paper). To hark back to the discussion of transparency in Section 1, though, note that the upshot of the lines of thought just sketched is that temporally speaking, as it were, experience in fact lacks any positive such structural features. ${ }^{23}$ As I said before, there seems to be no scope within

20. I am grateful to an anonymous referee for prompting me to clarify this point.

21. Compare here also Campbell's related point that "the egocentric frame used in vision employs monadic spatial notions, such as 'to the right', 'to the left', 'above', 'in front', and so on", rather than relational ones (1994: 119).

22. On this, see also Richardson (2014: 496). An idea along these lines also seems to be in play in Martin's (1992: 197) claim that a "structural difference between sight and touch" can ground a distinction between the two senses even in cases involving the perception of common sensibles that can be perceived with both of those senses, such as shape. Peacocke $(1983 ; 2008)$ similarly defends the idea that experience has 'sensational properties' in addition to representational ones, drawing in part on considerations concerning visual perspective, though his notion of a sensational property of experience seems to overlap only partly with that of a structural property, as understood, e.g., by Richardson.

23. Here I differ from Richardson, who claims that there is a temporal field analogous to the visual field, which, like the latter, constitutes a structural feature of experience. Obviously, matters here depend greatly on how one wants to define what counts as a structural feature of experience. However, note that, as I said, Richardson considers the existence of particular structural features of experience to be a matter not of what is being perceived, but of how things are being perceived. Yet, it is debatable whether the rationale she gives for talking about a temporal field fits with this characterization. What she calls the temporal field is the particular interval within which things have to change sufficiently for us to perceive the change, as shown by the fact that we can only 
a description of our experience of temporal properties for a distinction between those experienced properties themselves and a point in time from which they are experienced, and correspondingly a way in which those temporal properties are experienced that would also allow for other, alternative, ways in which they might be experienced. Thus, where some philosophers find themselves apparently drawn towards denying that negative transparency holds for temporal properties of experience, what they actually should be seen to be trying to get at is that, when it comes to time, there is a sense in which transparency might be seen to apply in its strongest form. The temporal properties of experience emphatically do not constitute an exception to negative transparency, even if there are other properties of experience, such as the way in which experience is spatially viewpointed, that do.

If these considerations are along the right lines, I think they also provide in a more general way for an understanding of the issues at stake in the intuition of an intimate connection between experiential presence and temporal presence. Interestingly, they imply that this intuition should not actually be seen as entailing that perceptual experience is best described as presenting us with events as being present. On the contrary, it is in fact an important feature of the phenomenology of perceptual experience that nothing equivalent to tense features in it. Temporally speaking, there is a sense in which things are not given to us under any 'mode of presentation' at all in sensory perception. In fact, it is just this, I want to suggest, which explains the special, sui generis, phenomenological character of perceptual experience, that is, the particularly direct way in which temporally present events figure in sensory awareness that the notion of experiential presence tries to capture.

As we have seen, Balashov, too, speaks of a special phenomenological feature specific to perceptual experience, which he terms Occurrence, and which he claims grounds some of the intuitions behind the A-theory of time, including the idea that the present is metaphysically special. Might it in fact be the very same aspect of perceptual experience just noted - the fact that it is not temporally viewpointed - that also stands behind this way of making a connection between the nature of experience and the (apparent) nature of time itself? If experience is not temporally viewpointed-does not present the experienced events under any 'temporal mode of presentation' - this does indeed provide for an intuitive sense in which it simply presents us with the bare occurrence of the events that figure in it. But why should this incline us towards adopting a particular metaphysical view of time?

perceive certain kinds of changes, whereas others happen too slowly for us to perceive them. Thus characterized, though, it is not clear to me that the contribution the existence of this 'temporal field' makes to experience should be seen to lie on the level of how things are being perceived, rather than the level of what we can perceive. 
Above I briefly mentioned the idea that the structural features of perceptual experience reflect the enabling conditions of perception in the different modalities. ${ }^{24}$ In visuo-spatial perception, for instance, part of what is manifest in the experience itself is how what a subject can see depends on where she is located: In so far as she can distinguish between the location of the objects seen and the location from which they are seen, she can also grasp the dependence of the visibility of those objects, and of the way they figure in her experience, on her own position. In this way, the character of her experience itself reveals to the subject the reason why she perceives the particular objects she does and not others, and that this is some fact about her. ${ }^{25}$

In so far as experience is not similarly temporally viewpointed, however, there is another aspect of what puts us into a position to perceive only certain items, and not others, that experience itself is silent on. When we experience an event, we experience that event to the exclusion of others that happen earlier or later, but nothing in our experience signals that this is due to anything to do with us - as I said above, there is a sense in which what we experience is just the bare occurrence of that event. Thus, the nature of our experience invites instead the thought that the fact that we experience this event and not the others must have a metaphysical explanation: for example, that it is just this present event that is real or in some other way metaphysically special, whereas past and future events are not. ${ }^{26} 27$

What I am suggesting, then, is that it is one and the same feature of the phenomenology of perceptual experience that can explain the appeal both behind the thought that the temporal properties of experience constitute an exception to transparency, and behind the thought that the present is somehow metaphysi-

24. Or, more specifically, what Richardson (2015) refers to as the 'Strawsonian enabling conditions' because of the special place they have in Strawson's (1974) account of perception. They contrast with other enabling conditions of perception that have to do, for instance, with having an intact visual system.

25. Related ideas play a crucial role in Evans's (1982: 222) idea of a what has been called a 'simple theory of perception' (Campbell 1994: 207) underpinning our grasp of the objectivity of the objects of perceptual experience.

26. Soteriou at one point develops a structurally somewhat similar line of thought, though he frames it in terms of the different idea that

there are reasons to think that we are perceptually aware of intervals of time, within which objects and events are perceived [but] the extent of the temporal interval one is aware of doesn't seem to one to be determined by one's sensory limitations. (2013: 132)

27. As against this argument, an anonymous referee raises the worry that it might overgeneralize, on the grounds that one might, e.g., also think that vision doesn't give us the material to explain why we can't see the insides of solid objects, but this doesn't lead us to metaphysical speculations about those insides. I would deny that vision doesn't give us the material to explain why we don't see the insides of objects. To see an object as solid (and opaque) is precisely to see its surfaces as blocking visual access to its insides - to constitute "site(s) of visual resistance" in Kalderon's (2015: 53) words. On related issues see also Richardson (2010) and Crowther (in press). 
cally special. As I have also tried to bring out, though, the appeal, in each case, is in fact misleading. There is a sense in which the transparency of experience actually applies in a particularly strong form to the temporal aspects of experience, in so far as experience lacks any structural features corresponding to the temporal enabling conditions of perception. And the same lack of such structural features can also explain our inclination to seek a metaphysical explanation for why we experience the particular events we do, and not past or future ones, rather than just explaining this to ourselves in terms of the timing of the relevant experiences themselves. ${ }^{28}$

\section{Concluding Remarks}

At the beginning of this paper, I mentioned O'Shaughnessy's view that, in conscious experience, subjects stand in a "special cognitive relation to the present moment, not accessible to non-experiencers" (2000: 50), and also "that the bond between time and experience is of great significance" (2000: 49). As I also went on to point out, though, given how frequently the idea of an intimate connection between experiential presence and temporal presence is invoked by philosophers-along, at least sometimes, with the idea that this connection goes to the very heart of the nature of perceptual consciousness - the substance behind it can nevertheless come to appear elusive if all we have to go on is the bare intuition that there is such a connection.

My aim in this paper has been to uncover the real substance behind the intuition that there is an intimate connection between experiential and temporal presence, by looking at two more specific debates in which this intuition can be seen to play a key role: the debate as to whether the temporal properties of experience constitute an exception to the transparency of experience, and the debate as to whether there are aspects of experience that give grounds for thinking that the present is metaphysically special. In each case, I have suggested, the relevant feature of the phenomenology of experience that philosophers have been trying to get at is actually the fact that perceptual experience is not temporally viewpointed. Temporally speaking, it lacks any positive structural features, and,

28. This is not meant as a comprehensive account of what underlies our tendency to think about time in the kinds of ways captured by the A-theory. I have focused specifically on the idea that the present is somehow metaphysically special as, e.g., expressed in the presentist's claim that only the present is real. I take it that there are a number of separate aspects to the A-theoretical picture, each of which might have a different psychological source. These include also the idea that the present marks the boundary between two metaphysically different regions of time, or the idea that time objectively passes. For an overview of other aspects of our psychology that might factor into the intuitive attractiveness of the A-theory, see, e.g., Deng (2017). See also Hoerl (2014a; $2014 \mathrm{~b}$ ) on related issues. 
correspondingly, there is no 'way' in which the temporal properties of goingson in the world are experienced, which would also allow for alternative ways of experiencing the same properties.

In effect, one upshot of my discussion has been that it is actually somewhat misleading to characterize the particularly direct way in which we are confronted with events in perceptual experience-the sense in which we might be said to simply experience their bare occurrence - in terms of the idea of there being an intimate connection between experiential and temporal presence. Or at least this should not be seen to imply that we experience events as present. In fact, nothing equivalent to tense (whether 'past', 'future', or 'present') features in perceptual experience, ${ }^{29}$ and that is what explains the special way in which events figure in experience-the sense in which they are simply experienced as occurring.

Another way to put the point here is that there is an important sense in which the way in which experience puts us in touch with events is not a matter of representation. In memory, we represent events as past; in anticipation, we represent them as future, but when we encounter events in perception, there is an aspect of our knowledge of when they happen that is not similarly a matter of our experience having a certain representational content. This, I take it, is part of what explains the sui generis nature of perceptual experience, as compared to, for example, both memory and anticipation - the sense in which it belongs to a phenomenological category all of its own. It is one reason for thinking "that the bond between time and experience is of great significance" (O'Shaughnessy 2000: 49).

\section{Acknowledgments}

For helpful comments, I am grateful to two anonymous referees, to audiences at workshops in Berlin, St. Andrews, Glasgow, London and Milan, and to members of the Warwick Mind and Action Research Seminar. Part of the work on this pa-

29. An anonymous reviewer asks whether this isn't in tension with the fact that we make justified tensed judgements on the basis of experience. It is true that my view implies that such judgements have to involve a transition from a mental state involving nothing equivalent to tense to one involving tense. But we are already familiar with other examples of such transitions. Here I am in agreement, for instance, with Prosser's (2006) suggestion that the way we arrive at tensed judgements on the basis of perceptual experience might be modelled, in certain respects, after the move from the thought 'It is raining' (construed as containing the thinker's location as an 'unarticulated constituent' in Perry's (1986), terminology) to the thought 'It is raining here'. Similarly, Campbell (1994) discusses the question as to how vision can ground judgements involving the first person, even though the first person does not figure amongst the items perceived. Saying that there are such parallels of course does not imply that there aren't any substantive questions about what justifies the relevant transitions in each case (as Campbell's discussion in particular brings out). But I think that is a topic for another occasion. 
per was supported by grant AH/Poo217X/1 from the UK Arts and Humanities Research Council for the project 'Time: Between Metaphysics and Psychology'.

\section{References}

Allen, Keith (2013). Blur. Philosophical Studies, 162(2), 257-273. https://doi.org/10.1007/ s11098-011-9758-6

Balashov, Yuri (2005). Times of Our Lives: Negotiating the Presence of Experience. American Philosophical Quarterly, 42(4), 295-309.

Broad, C. D. (1925). The Mind and Its Place in Nature. Kegan Paul, Trench, Trubner \& Co.

Butterfield, Jeremy (1984). Seeing the Present. Mind, 93(370), 161-176. https://doi. org/10.1093/mind/XCIII.370.161

Callender, Craig (2008). The Common Now. Philosophical Issues, 18(1), 339-361. https:// doi.org/10.1111/j.1533-6077.2008.00151.x

Campbell, John (1994). Past, Space and Self. MIT Press.

Crane, Tim (2006). Is There a Perceptual Relation? In Tamar Szabó Gendler and John Hawthorne (Eds.), Perceptual Experience (126-146). Oxford University Press. https:// doi.org/10.1093/acprof:oso/9780199289769.003.0004

Crowther, Thomas (in press). In Touch with the Look of Solidity. In Thomas Crowther and Clare Mac Cumhaill (Eds.), Perceptual Ephemera. Oxford University Press.

Deng, Natalja (2017). Temporal Experience and the A versus B Debate. In Ian Phillips (Ed.), The Routledge Handbook of Philosophy of Temporal Experience (239-248). Routledge.

Dennett, Daniel C. and Marcel Kinsbourne (1992). Time and the Observer: The Where and When of Consciousness in the Brain. Behavioral and Brain Sciences, 15(2), 183-201. https://doi.org/10.1017/S0140525X00068229

Dummett, Michael (1960). A Defense of McTaggart's Proof of the Unreality of Time. The Philosophical Review, 69(4), 497-504. https://doi.org/10.2307/2183483

Dummett, Michael (1973). Frege: Philosophy of Language. Duckworth.

Evans, Gareth (1982). The Varieties of Reference. John McDowell (Ed.). Clarendon Press.

Falk, Arthur (2003). Time Plus the Whoosh and Whiz. In Aleksandar Jokić and Quentin Smith (Eds.), Time, Tense, and Reference (211-250). MIT Press.

Fine, Kit (2006). The Reality of Tense. Synthese, 150(3), 399-414. https://doi.org/10.1007/ s11229-005-5515-8

Frischhut, Akiko M. (2014). Diachronic Unity and Temporal Transparency. Journal of Consciousness Studies, 21(7-8), 34-55.

Grush, Rick (2016). On the Temporal Character of Temporal Experience, Its Scale NonInvariance, and Its Small Scale Structure. doi:10.21224/P4 $\mathrm{PC}_{73}$

Hoerl, Christoph (1998). The Perception of Time and the Notion of a Point of View. European Journal of Philosophy, 6(2), 156-171. https://doi.org/10.1111/1468-0378.00056

Hoerl, Christoph (2009). Time and Tense in Perceptual Experience. Philosophers' Imprint, 9(12), 1-18.

Hoerl, Christoph (2014a). Do We (Seem to) Perceive Passage? Philosophical Explorations, 17(2), 188-202. https://doi.org/10.1080/13869795.2013.852615 
Hoerl, Christoph (2014b). Time and the Domain of Consciousness. Annals of the New York Academy of Sciences, 1326(1), 90-96. https://doi.org/10.1111/nyas.12471

Husserl, Edmund (1893-1917). On the Phenomenology of Consciousness of Internal Time (reprint ed.) (John Barnett Brough, Trans.). Kluwer Academic Publishers.

James, William (1909). A Pluralistic Universe: Hibbert Lectures at Manchester College on the Present Situation in Philosophy. Longmans, Green and Co.

Kalderon, Mark Eli (2015). Form without Matter: Empedocles and Aristotle on Color Perception. Oxford University Press. https://doi.org/10.1093/acprof:oso/9780198717904.001.0001

Le Poidevin, Robin (2007). The Images of Time: An Essay on Temporal Representation. Oxford University Press. https://doi.org/10.1093/acprof:oso/9780199265893.001.0001

Lee, Geoffrey (2014). Extensionalism, Atomism and Continuity. In L. Nathan Oaklander (Ed.), Debates in the Metaphysics of Time. Bloomsbury.

Leininger, Lisa (2015). Presentism and the Myth of Passage. Australasian Journal of Philosophy, 93(4), 724-739. https://doi.org/10.1080/00048402.2015.1007463

Martin, M. G. F. (1992). Sight and Touch. In Tim Crane (Ed.), The Contents of Experience. Cambridge University Press. https://doi.org/10.1017/CBO9780511554582.010

McTaggart, J. Ellis (1908). The Unreality of Time. Mind, 17(68), 457-474. https://doi. org/10.1093/mind/XVII.4.457

Miller, Izchak (1984). Husserl, Perception, and Temporal Awareness. MIT Press.

Millikan, Ruth Garrett (1991). Perceptual Content and Fregean Myth. Mind, 100(4), 439459. https://doi.org/10.1093/mind/C.400.439

Moore, G. E. (1903). The Refutation of Idealism. Mind, 12(48), 433-453. https://doi. org/10.1093/mind/XII.4.433

Nerlich, Graham (1979). How to Make Things Have Happened. Canadian Journal of Philosophy, 9(1), 1-22. https://doi.org/10.1080/00455091.1979.10716233

O'Shaughnessy, Brian (2000). Consciousness and the World. Clarendon Press.

Paul, L. A. (2010). Temporal Experience. Journal of Philosophy, 107(7), 333-359. https://doi. org/10.5840/jphil2010107727

Peacocke, Christopher (1983). Sense and Content: Experience, Thought, and Their Relations. Clarendon Press.

Peacocke, Christopher (2008). Sensational Properties: Theses to Accept and Theses to Reject. Revue Internationale de Philosophie, 243(1), 7-24.

Perry, John (1986). Thought without Representation. Proceedings of the Aristotelian Society, Supplementary Volumes, 60, 137-152. https://doi.org/10.1093/aristoteliansupp/60.1.137

Phillips, Ian (2009). Experience and Time (Doctoral dissertation). University College London.

Phillips, Ian (2014a). Experience of and in Time. Philosophy Compass, 9(2), 131-144. https:// doi.org/10.1111/phc3.12107

Phillips, Ian (2014b). The Temporal Structure of Experience. In Valtteri Arstila and Dan Lloyd (Eds.), Subjective Time: The Philosophy, Psychology, and Neuroscience of Temporality (139-158). MIT Press.

Price, Huw (2011). The Flow of Time. In Craig Callender (Ed.), The Oxford Handbook of Philosophy of Time (276-311). Oxford University Press. https://doi.org/10.1093/oxfordhb/9780199298204.003.0010

Prosser, Simon (2006). Temporal Metaphysics in Z-Land. Synthese, 149(1), 77-96. https:// doi.org/10.1007/s11229-004-6249-8 
Richardson, Louise (2010). Seeing Empty Space. European Journal of Philosophy, 18(2), 227-243. https://doi.org/10.1111/j.1468-0378.2008.00341.x

Richardson, Louise (2014). Space, Time and Molyneux's Question. Ratio - New series, 27(4), 483-505. https://doi.org/10.1111/rati.12081

Richardson, Louise (2015). Perceptual Activity and Bodily Awareness. Proceedings of the Aristotelian Society, 115(2), 147-165. https://doi.org/10.1111/j.1467-9264.2015.00389.x

Russell, Bertrand (1912). The Problems of Philosophy. Oxford University Press.

Russell, Bertrand (1913). Theory of Knowledge: The 1913 Manuscript (reprint ed.). Elizabeth Ramsden Eames and Kenneth Blackwell (Eds.). George Allen \& Unwin.

Skow, Bradford (2011). Experience and the Passage of Time. Philosophical Perspectives, 25(1), 359-387. https://doi.org/10.1111/j.1520-8583.2011.00220.x

Soteriou, Matthew (2013). The Mind's Construction: The Ontology of Mind and Mental Action. Oxford University Press. https://doi.org/10.1093/acprof:oso/9780199678457.001.0001

Strawson, P. F. (1974). Causation in Perception. In Freedom and Resentment and Other Essays (66-84). Methuen.

Tye, Michael (2003). Consciousness and Persons: Unity and Identity. MIT Press.

Valberg, J. J. (1992). The Puzzle of Experience. Oxford University Press. https://doi. org/10.1093/acprof:oso/9780198242918.001.0001 